\title{
Preface: International symposium on catalytic conversion of energy and resources, 2016
}

\author{
O-Bong Yang' ${ }^{1}$ Jung-Min Sohn' ${ }^{2}$ Dae-Won Lee ${ }^{3}$
}

Published online: 11 April 2018

(C) Springer Science+Business Media B.V., part of Springer Nature 2018

An international symposium on catalytic conversion of energy and resources (ISCCER) was held in Seoul, Republic of Korea, from June 30 to July 2, 2016, as the satellite conference of the 16th international congress on catalysis (ICC). The symposium provided an encounter among the catalyst researchers with interest in the state-of-the-art scientific trends of the latest catalytic conversion processes of energy and resources to build the sustainable future. The symposium was attended by 228 participants from 11 nations. The program included 2 plenary lectures (Prof. Kazunari Domen and Prof. Alexis T. Bell), 6 keynote lectures, 5 invited lectures and 37 general oral presentations.

Especially, the symposium was organized to comemorate the retirement of Professor Seong Ihl Woo from KAIST (Korea Advanced Institute of Science and Technology). Since Professor Woo obtained his MS degree at KAIST in 1975, for the last 40 years, he has investigated the structure of catalysts, reaction mechanisms, surface chemistry, reactor design, and reaction kinetics related to olefin polymerization, semiconductor materials and processing, environment protection and energy conversion. High-throughput screening (HTS) methodology augmented by artificial

$\triangle$ O-Bong Yang

obyang@jbnu.ac.kr

Jung-Min Sohn

jmsohn@chonbuk.ac.kr

Dae-Won Lee

stayheavy@kangwon.ac.kr

1 School of Chemical Engineering, Chonbuk National University, Jeonju 54896, Republic of Korea

2 Department of Mineral Resources and Energy Engineering, Chonbuk National University, Jeonju 54896, Republic of Korea

3 Department of Chemical Engineering, Kangwon National University, Chuncheon 24341, Republic of Korea 
intelligence, was pioneered by Professor Woo, and was for the efficient discovery of desired catalysts and functional materials. Fuel cell technology has also been extensively investigated. Non-Pt, lean-Pt and carbon-based fuel cell electrode materials have been extensively developed. The electrical and/or photochemical activations of $\mathrm{CO}_{2}$ were recently actively pursued to make mankind and the earth sustainable for a long time. About 500 papers and 70 patents have been published and the total number of citations is more than 7000. Professor Who has contributed significantly to advancing the technology of olefin polymerization, catalysis, semiconductor processing, electronic materials, combinatorial/high-throughput screening, fuel cells and $\mathrm{CO}_{2}$ activation. No less than $68 \mathrm{PhD}$ theses, $71 \mathrm{MS}$ theses and 27 postdoctoral fellows have been advised by Professor Woo. He served more than 80 international conferences as chairman, secretary and committee member, and 10 plenary lectures, 12 keynote lectures and 190 invited talks have been given at many renowned conferences and organizations. He has received numerous awards including the Presidential Korean Engineering Award (2005), the National Medal of Science and Technology (2001), the Korean Institute of Chemical Engineers Academic Award (1997), the Pacific Northwest National Laboratory Distinguished Catalyst Lecturer (2005) and Yeo-San Catalysis Awards (2006).

This special issue of Research on Chemical Intermediates contains 17 papers that were originally presented at this symposium and selected through a strict review process. The guest editors would like to thank all the catalyst scientists and engineers who presented at the ISCCER, and especially the authors who contributed to this special issue. We also deeply appreciate all the contributors and reviewers who helped to ensure the quality of this issue. Finally, we would like to thank Prof. Seong Ihl Woo for providing his lifetime efforts and cooperation to the catalysis community.

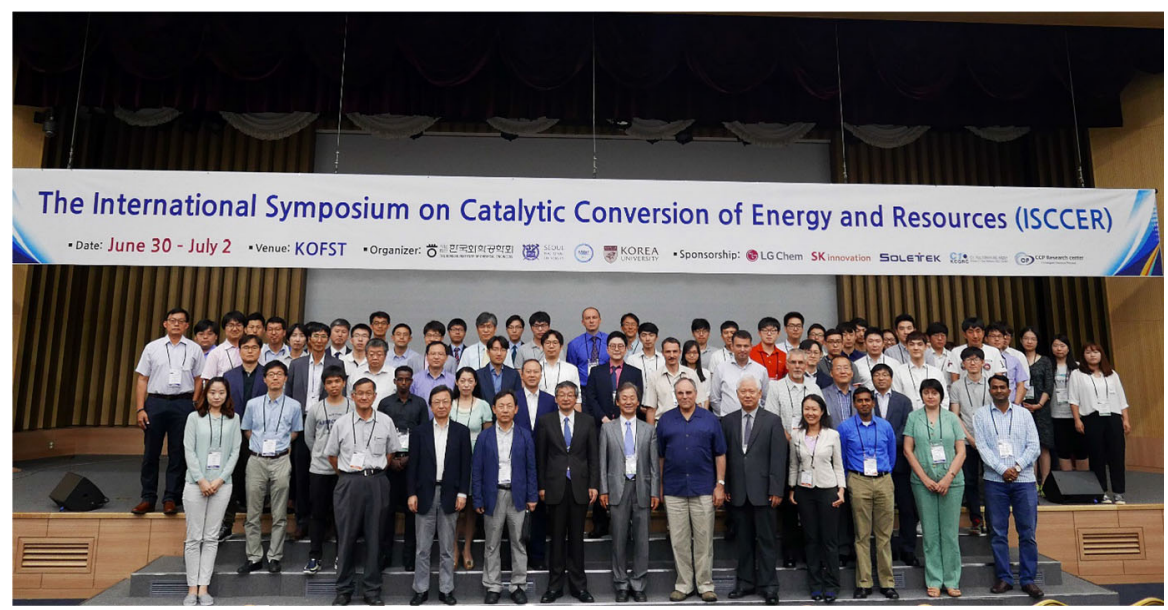

